\title{
Application of pulmonary rehabilitation in patients with pulmonary embolism (Review)
}

\author{
AIPING YU ${ }^{1}$, WEIPING DING ${ }^{1}$, WANMI LIN ${ }^{1}$, JUAN CAI $^{1}$ and WEINA HUANG ${ }^{2}$ \\ Departments of ${ }^{1}$ Nursing and ${ }^{2}$ Respiratory and Critical Care Medicine, Ningbo First Hospital, \\ Ningbo, Zhejiang 315000, P.R. China
}

Received August 3, 2021; Accepted November 9, 2021

DOI: $10.3892 /$ etm.2021.11019

\begin{abstract}
As a common clinical emergency, pulmonary embolism (PE) is the third most fatal cardiovascular disease worldwide. Although current sophisticated medical technology has considerably improved the prognosis of patients with PE, they remain at risk of developing long-term complications such as post-PE syndrome. Pulmonary rehabilitation is of great value for patients with chronic lung diseases since it can improve their quality of life while also relieving clinical symptoms. Rehabilitation therapy has been demonstrated to improve recovery and prognosis of patients with PE. Due to short implementation time and the small number of studies, its effectiveness and safety in PE warrant further investigation. The present review focused on elucidating PE pathogenesis, post-PE syndrome and the clinical application of pulmonary rehabilitation in patients with $\mathrm{PE}$.
\end{abstract}

\section{Contents}

1. Introduction

2. Etiology, pathogenesis and susceptibility factors of PE

3. Post-PE syndrome

4. Pulmonary rehabilitation

5. Clinical implications of pulmonary rehabilitation

6. Discussion

7. Conclusion

\section{Introduction}

Pulmonary embolism (PE) is characterized by pulmonary circulation and respiratory dysfunction caused by various

Correspondence to: Professor Aiping Yu, Department of Nursing, Ningbo First Hospital, 59 Liuting Road, Ningbo, Zhejiang 315000, P.R. China

E-mail: yuaiping11@126.com

Key words: pulmonary embolism, post-pulmonary embolism syndrome, pulmonary rehabilitation, clinical application emboli (1). The clinical symptoms of PE include chest pain, hemoptysis and dyspnea. An analysis of vital registration data between 2013 and 2015 from the WHO Mortality Database revealed that, between the ages of 15 and 55, 8-13 per 1,000 women and 2-7 per 1,000 men in Europe die due to PE per year (2). The rapid advancement of medical diagnostic technologies has resulted in a progressive increase in the rate of PE diagnosis. Recent years have demonstrated a substantial improvement in the prognosis of PE due to early effective interventions, such as hemodynamics and respiratory support, anticoagulation therapy and reperfusion therapy, which have decreased the mortality rate of acute PE (3).

Although symptoms can generally be improved within 3-6 months following effective treatment, most acute PE survivors are at risk of long-term adverse outcomes, such as impaired quality of life and activity tolerance (4-6). The past few decades have mainly focused on diagnosis and in-hospital treatment; thus, by ignoring rehabilitation importance, long-term adverse symptoms have remained unaddressed (7). Sequential therapy for patients with PE outside hospital and at home is equally important, which to a certain extent could effectively reduce thrombosis recurrence and improve prognosis.

In 2019, European Society of Cardiology guidelines for diagnosis and management of acute PE recommended an effective follow-up strategy for patients with persistent symptoms following PE, including exercise rehabilitation, treatment of comorbidities, behavioral education and modulation of risk factors (3). As an important component of chronic lung disease management, pulmonary rehabilitation is mainly used for patients with chronic obstructive pulmonary disease (COPD) (8), which can improve their long-term physical and mental conditions, and quality of life (9-12). A retrospective study determined that initiating pulmonary rehabilitation within 3 months after hospitalization was significantly associated with lower mortality risk at 1 year of discharge from the index hospitalization for patients with COPD (13).

Recently, applying pulmonary rehabilitation to patients with other types of pulmonary diseases (such as PE) has garnered considerable attention from clinicians $(14,15)$. Similar to COPD, patients with PE experience varying degrees of respiratory symptoms and impaired motor function (16). A Chinese study conducted a 6 -week low-intensity exercise training program on 80 patients with acute PE. The findings indicated 
that exercise training was beneficial to patient recovery (17). Unfortunately, to the best of our knowledge, there remains no unified standard of long-term rehabilitation for patients with PE and only a few studies have investigated the efficacy and safety of rehabilitation after PE $(14,18,19)$. The present review detailed the etiology, pathogenesis and susceptibility factors of $\mathrm{PE}$, post-PE syndrome and clinical application of pulmonary rehabilitation in patients with PE. The details of the literature search strategy are presented in Data S1.

\section{Etiology, pathogenesis and susceptibility factors of PE}

Venous thromboembolism (VTE) is a multifactorial disease that involves deep vein thrombosis and PE, which is caused by congenital or acquired pathophysiological changes that result in venous blood flow disturbance or arrest (20). Typically, PE is caused when pulmonary artery blockage, caused by a venous embolus in the lower extremities, falls off, resulting in dysfunction of the pulmonary circulation and the right atrium (21).

PE might share the pathogenic factors with VTE, which can be roughly divided into congenital and acquired factors (22). A previous statement revealed that certain genetic factors may increase VTE and PE risks, such as factor V Leiden mutations, activated protein $\mathrm{C}$ resistance, prothrombin (factor II) G20210A mutation, protein S deficiency and antithrombin deficiency (23). The acquired risk factors include postoperative states, pregnancy, malignancy and age (24). Major trauma, surgery, lower-limb fractures, joint replacements and spinal cord injury are also strong risk factors for PE (3).

\section{Post-PE syndrome}

Following the occurrence of acute PE, $50 \%$ of patients experience a series of clinical manifestations, such as persistent dyspnea and impaired activity tolerance and quality of life due to abnormal pulmonary hemodynamics, gas exchange and cardiopulmonary function $(25,26)$. If the residual symptoms and defects are not effectively improved, they eventually lead to chronic thromboembolic pulmonary hypertension (CTEPH) and even death. In China, 614 cases of acute PE were followed up for a median of 3.3 years, the results of which revealed that the 1-,2- and 3-year cumulative incidences of CTEPH were 0.8 , 1.3 and $1.7 \%$, respectively (27). A meta-analysis also revealed that up to $3 \%$ of patients with PE suffer from CTEPH (28).

In 2014, Klok et al (29) first proposed the concept of 'post-PE syndrome', which guides the long-term monitoring, management and follow-up of patients with PE. Its definition specifically refers to clinical syndromes lasting $>3$ months following acute PE occurrence and are mainly manifested by dyspnea, activity limitation and decline in physical function status or quality of life (29). The occurrence and development of post-PE syndrome are mainly influenced by residual thrombosis after PE, hemodynamic changes and changes in cardiopulmonary function (29). After receiving appropriate treatment, up to $50 \%$ of patients continue to experience these residual symptoms and defects (30). For instance, compared with the general population and matched controls, patients with a history of PE have a reduced functional capacity and persistent dyspnea, resulting in impaired health-related quality of life (26).
In recent years, the occurrence of such clinical sequelae has garnered increasing attention (31-33). The prospective multicenter cohort study (Evaluation of Long-term Outcomes after Pulmonary Embolism study) revealed that $46.8 \%$ of patients with PE had movement limitation, dyspnea and reduced quality of life at the onset of a 1-year follow-up. In addition, male sex, low age of onset, high BMI and smoking history were independent predictors of post-PE syndrome $(34,35)$. According to a Follow-up after Acute Pulmonary Embolism study, the median PE-quality of life score decreased from 3 to 12 months (from 19.4 to $13.0 \%$ ) (36). To reverse this trend, a multidisciplinary team (including physicians, qualified nurses and other associated professionals) should provide comprehensive treatment for patients with PE during hospitalization and after discharge, and also optimize long-term management to improve prognosis.

\section{Pulmonary rehabilitation}

Pulmonary rehabilitation is a comprehensive intervention program that combines multiple measures and disciplines, including but not limited to exercise training, education and behavioral changes (Fig. 1) (37). Its objectives are to enhance the physical and mental status of patients with chronic respiratory diseases, and promote long-term health (38). Although pulmonary rehabilitation is mainly applied in patients with COPD, it also includes patients with other chronic respiratory diseases, such as asthma, pulmonary hypertension, interstitial lung disease, pneumoconiosis and even those with end-stage lung disease (37).

Exercise training. As the core of pulmonary rehabilitation therapy, exercise training can improve skeletal muscle function, cardiopulmonary adaptability and exercise tolerance while also relieving dyspnea symptoms. The content of exercise training is diverse, including interval training and resistance training. Notably, exercise training should ensure the rationality of the training program, allowing for smooth long-term and stable training and thereby improving the effect of the training.

The exercise training can be divided into upper and lower limb muscle strength training. Upper limb training includes dumbbell lifting and chest expansion exercises, whereas lower limb training includes walking, cycling, straight leg raising exercises and knee extension training. The Pulmonary Rehabilitation Guidelines of the American Thoracic Society and the European Respiratory Society revealed that lower extremity muscle exercise is important in improving the dyspnea symptoms of patients and enhancing exercise endurance (8). Moreover, upper limb training can improve fatigue. Therefore, upper and lower extremity muscle exercises should be simultaneously conducted to improve the effectiveness of exercise therapy.

Respiratory training. Respiratory training is an important component of pulmonary rehabilitation since it focuses on strengthening breathing muscles. Load training can drill the inspiratory auxiliary muscles and diaphragm muscles to increase endurance and the strength of muscles, thereby improving respiration. Several studies have demonstrated that 


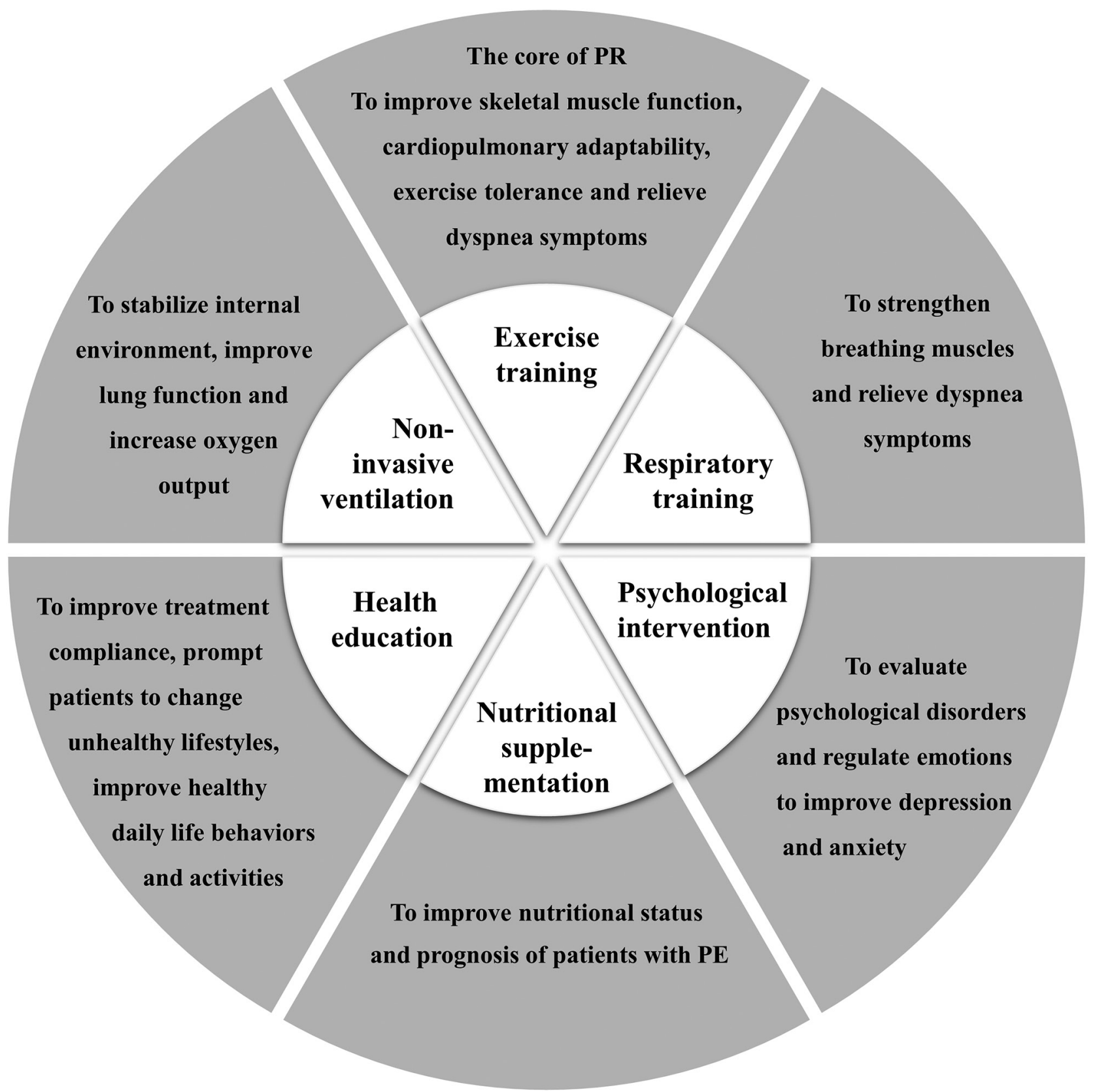

Figure 1. Diagram of pulmonary rehabilitation treatment for pulmonary embolism. Pulmonary rehabilitation is a comprehensive intervention program, mainly including exercise training, respiratory training, non-invasive ventilation, health education, psychological intervention and nutritional supplementation. Exercise training is the core of pulmonary rehabilitation.

respiratory training can significantly increase the maximum inspiratory pressure and maximum tidal volume for patients with chronic respiratory diseases, eventually improving their inspiratory muscle endurance, exercise endurance and quality of life (39-41). For patients with PE, respiratory exercises should be performed if the condition permits. According to rehabilitation physician assessment, patients with PE may benefit from increasing their breathing muscle training or exercising with a breathing training device, improving breathing endurance and relieving dyspnea symptoms $(42,43)$.

Non-invasive ventilation. Non-invasive ventilation is a common pulmonary rehabilitation measure, which can stabilize internal environment, improve lung function and increase oxygen output (44). Applying non-invasive ventilation in patients with COPD has been developed, and studies have demonstrated its significant beneficial impact on quality of life by improving exercise capacity, respiratory function and reducing dynamic malignant inflation and dyspnea $(44,45)$. A novel form of home non-invasive ventilation has emerged, bringing convenience to the pulmonary rehabilitation of patients (46). However, non-invasive ventilation also has certain risks, such as diaphragm damage (47). As a result, exploring solutions to reduce mechanical ventilation injuries is required in the future.

Health education. Health education is a systematic, planned and organized process for educating patients on the disease itself and how to prevent embolism recurrences, as well as the 
significance of pulmonary rehabilitation treatment (37). Health education can enable patients to clarify treatment methods and precautions of the disease and improve their consciousness of respiratory rehabilitation and exercise training. It can also motivate patients to regulate medication and develop healthy living habits, thereby delaying the decline in lung function (48). Therefore, it is important to provide adequate health education for patients to improve treatment compliance, prompt patients to change unhealthy lifestyles and improve healthy daily life behaviors or activities (49).

Psychological intervention. Due to long-term suffering, patients frequently exhibit depression or irritability in addition to physical discomfort $(50,51)$. The majority of patients with acute PE are afraid of the direct trauma caused by the disease and the potential for death. Even survivors will experience long-term psychological imbalances due to their fear of recurrence, which eventually results in lifestyle and behavioral changes $(30,52)$. An observational study of patients with acute PE with a median follow-up of 60 months revealed that patients usually experience changes in behavior, reduced physical activity and even post-traumatic stress (53). A nested qualitative study was conducted to observe the thoughts, feelings and experiences of patients throughout the early stages of acute PE recovery and to explore strategies for restoring daily life behavior and physical activity (54). During hospitalization, clinical symptoms are gradually alleviated with the help of professional doctors and nurses. However, after being discharged from hospital, they may continue to experience anxiety due to a lack of opportunity for close communication with specialists (54). A systematic review and meta-analysis revealed that patients with mental illnesses are at increased risk of VTE due to hypercoagulability and stasis (55). This is a vicious circle that not only aggravates symptoms of $\mathrm{PE}$ but also deteriorates the mental state. Accordingly, mental health cannot be ignored during the PE treatment process. In pulmonary rehabilitation, patients should learn to better regulate their emotions to improve their depression and anxiety, such as training on emotional awareness, selecting and attending to stressors and modulating emotional reactions (56). In addition, physicians should routinely evaluate whether patients have psychological disorders.

Nutritional supplementation. In addition to the gradual decrease of lung function in patients with $\mathrm{PE}$, malnutrition is a typical complication, impairing the disease's outcome (57). Therefore, nutritional assessment and intervention should be initiated promptly for patients with PE. Previous studies suggested that patients should achieve nutritional interventions by adjusting their diet, such as low-carbohydrate and high-protein diets supplemented with potassium, magnesium, phosphorus, zinc and other trace elements and vitamins $(58,59)$. Increased protein intake in the diet increases the total muscle mass, which improves respiratory muscle function (57). However, there are currently few studies on nutritional interventions for patients with PE. Therefore, additional research is required to confirm the impact of nutritional interventions on patient recovery in order to rationally apply nutritional interventions in the future.
In summary, pulmonary rehabilitation requires interdisciplinary collaboration to provide a full range of interventions for patients with PE regarding disease management, symptom alleviation, respiratory function maintenance, psychological intervention and nutritional supplementation. American College of Chest Physicians/American Association of Cardiovascular and Pulmonary Rehabilitation proposes that the content of level A in pulmonary rehabilitation is exercise training. Level B is non-invasive ventilation, breathing muscle exercises and health education, whereas level $\mathrm{C}$ is nutritional supplementation (60). Furthermore, clinicians should choose appropriate individualized treatment methods to improve dyspnea and functional ability and, thus, reintegrate patients into daily life.

\section{Clinical implications of pulmonary rehabilitation}

As the importance of rehabilitation in the long-term management of PE has been recognized by the international community, it has gradually become more prevalent in clinical practice. Appropriate pulmonary rehabilitation could relieve acute symptoms and prevent or improve post-PE syndrome. However, the current data on pulmonary rehabilitation are limited in patients with PE (Table I).

After 3 months of follow-up, a randomized clinical trial for patients with acute VTE revealed that neither the exercise intervention group nor the control group experienced serious adverse events (18). In addition, the exercise intervention group had a significantly reduced BMI and significantly increased physical activity and maximum oxygen consumption compared with the control group. Nopp et al (19) revealed that the exercise capacity of 22 patients with PE exhibiting persistent symptoms and undergoing an out-patient multi-professional 6-week pulmonary rehabilitation program were significantly improved. In the Netherlands, an observational cohort study revealed that a 12 -week out-patient pulmonary rehabilitation program that included sports and psychological counseling, effectively improved patient symptoms (14). Noack et al (61) retrospectively analyzed the role of a 3 -week in-patient rehabilitation program for patients with $\mathrm{PE}$, which suggested that pulmonary rehabilitation programs following PE might be considered safe. Low-to-moderate-intensity exercise therapy following acute PE is considered safe in the United States (62). German researchers have established a personalized exercise and rehabilitation program for intermediate- and high-risk patients with PE based on their clinical characteristics (physical fitness, primary disease severity, comorbidities and other confounding factors) (63). The results indicated no serious adverse events during rehabilitation processes, such as bleeding, rehospitalization or death due to VTE. Furthermore, the mortality rate of patients receiving rehabilitation during hospitalization and at 12 months follow-up was 0 and $5.7 \%$, respectively. This prospective study demonstrated that pulmonary rehabilitation is both safe and effective for patients with PE (63), implying the potential application value of pulmonary rehabilitation. However, the conclusion was limited by the small number of patients and the lack of a control group. Large-scale prospective studies are required to identify the benefits of pulmonary rehabilitation for patients with PE. 
Table I. Clinical implications of pulmonary rehabilitation for patients with PE.

\begin{tabular}{|c|c|c|c|c|c|c|}
\hline Author & Year & Region & Research type & Rehabilitation program & Results & (Refs.) \\
\hline Lakoski et al & 2015 & USA & $\begin{array}{l}\text { Randomized } \\
\text { clinical trial }\end{array}$ & $\begin{array}{l}\text { The program included exercise } \\
\text { training and a behavioral weight } \\
\text { loss program focused on } \\
\text { moderate-intensity, high-volume } \\
\text { physical activity to increase } \\
\text { energy expenditure and promote } \\
\text { weight loss }\end{array}$ & $\begin{array}{l}\text { Early initiation of exercise } \\
\text { training improved physical } \\
\text { activity and fitness without } \\
\text { adverse events }\end{array}$ & (18) \\
\hline Noack et al & 2015 & Germany & $\begin{array}{l}\text { Retrospective } \\
\text { study }\end{array}$ & $\begin{array}{l}\text { A 3-week in-patient rehabilitation } \\
\text { program including Nordic } \\
\text { walking, medical training therapy, } \\
\text { intensive gymnastics/exercise } \\
\text { and pulmonological functional } \\
\text { exercise }\end{array}$ & $\begin{array}{l}\text { The standard rehabilitation } \\
\text { program after PE was safe }\end{array}$ & (61) \\
\hline Amoury et al & 2018 & Germany & $\begin{array}{l}\text { Prospective } \\
\text { study }\end{array}$ & $\begin{array}{l}\text { A personalized } \\
\text { rehabilitation program, including } \\
\text { exercise training, breathing } \\
\text { training, attending seminars and } \\
\text { lectures, and psychosocial } \\
\text { support }\end{array}$ & $\begin{array}{l}\text { Mortality and other serious } \\
\text { event rates (hospital admission, } \\
\text { bleeding complications and } \\
\text { thromboembolic events) were } \\
\text { low during hospital admission } \\
\text { and in the 12-month follow-up } \\
\text { period }\end{array}$ & (63) \\
\hline Rolving et al & 2020 & Denmark & $\begin{array}{l}\text { Randomized } \\
\text { clinical } \\
\text { trial }\end{array}$ & $\begin{array}{l}\text { A brief nurse consultation and an } \\
8 \text {-week home-based exercise } \\
\text { program }\end{array}$ & $\begin{array}{l}\text { Exercise capacity and dyspnea } \\
\text { symptoms did not improve. No } \\
\text { additional adverse events were } \\
\text { documented }\end{array}$ & (64) \\
\hline Nopp et al & 2020 & Austria & $\begin{array}{l}\text { Prospective } \\
\text { study }\end{array}$ & $\begin{array}{l}\text { Endurance, strength and } \\
\text { inspiratory muscle training over at } \\
\text { least } 6 \text { weeks (three times a week } \\
\text { for } 3-4 \mathrm{~h} \text { ); individualized patient } \\
\text { education including disease- and } \\
\text { medical treatment-specific } \\
\text { seminars, nutritional counseling } \\
\text { and smoking cessation sessions }\end{array}$ & $\begin{array}{l}\text { The } 6 \text { min walk experiment } \\
\text { demonstrated improved results. } \\
\text { Maximum strength, endurance } \\
\text { and inspiratory muscle strength } \\
\text { was also improved. The health } \\
\text { of } 78 \% \text { of patients improved } \\
\text { during long-term follow-up }\end{array}$ & (19) \\
\hline $\begin{array}{l}\text { Cires-Drouet } \\
\text { et al }\end{array}$ & 2020 & USA & $\begin{array}{l}\text { Prospective } \\
\text { study }\end{array}$ & $\begin{array}{l}\text { A 3-month exercise program } \\
\text { (exercise training was conducted } \\
\text { in three phases) }\end{array}$ & $\begin{array}{l}\text { Low-to-moderate intensity } \\
\text { exercise therapy was safe after } \\
\text { acute PE }\end{array}$ & (62) \\
\hline Boon et al & 2021 & $\begin{array}{l}\text { Nether- } \\
\text { lands }\end{array}$ & $\begin{array}{l}\text { Observational } \\
\text { cohort study }\end{array}$ & $\begin{array}{l}\text { A } 12 \text {-week out-patient pulmonary } \\
\text { rehabilitation program, including } \\
\text { endurance exercise training, } \\
\text { strength exercise training, } \\
\text { pulmonologist consultation, } \\
\text { physiotherapist consultation }\end{array}$ & $\begin{array}{l}\text { Improved training intensity, } \\
\text { PE-specific quality of life, } \\
\text { fatigue and functional status }\end{array}$ & (14) \\
\hline $\begin{array}{l}\text { Haukeland- } \\
\text { Parker et al }\end{array}$ & 2021 & Norway & $\begin{array}{l}\text { Randomized } \\
\text { control } \\
\text { trial }\end{array}$ & $\begin{array}{l}\text { A basic pulmonary rehabilitation } \\
\text { program consisting of a } \\
\text { supervised, out-patient exercise } \\
\text { program for } 1 \mathrm{~h} \text { twice weekly } \\
\text { for eight weeks and an } \\
\text { educational session }\end{array}$ & $\begin{array}{l}\text { The trial has not been } \\
\text { completed }\end{array}$ & $(65)$ \\
\hline
\end{tabular}

PE, pulmonary embolism.

Rolving et al (64) conducted a randomized controlled trial on patients that were newly diagnosed with PE to study the effect of rehabilitation intervention on early physical fitness and quality of life. After 8 weeks of home-based exercise with nurse consultation, the results indicated that home-based exercise did not further improve exercise 
capacity or dyspnea symptoms of patients with PE but also did not cause additional adverse events. Nevertheless, this trial had a short follow-up time and included patients with newly diagnosed PE. For newly diagnosed patients with PE, their acute symptoms can be relieved after active early clinical intervention (7). As the disease continues, the impact of rehabilitation therapy on patients with PE may become increasingly evident (64). A two-center randomized controlled trial is ongoing (Clinical Trial no. NCT03405480). The intervention involves individually adapted exercises based on existing pulmonary rehabilitation programs (relaxation, interval and resistance training) and an educational session ( 8 weeks). The physical capacity, dyspnea and quality of life of intervention and control groups were compared after 12 and 36 weeks (65).

\section{Discussion}

As a cardiovascular disease, PE is a common emergency in internal medicine, ranking third in terms of mortality after myocardial infarction and stroke in China (from 1997 to 2008) and Europe (in 2014) $(66,67)$. With the continuous advancement of medical standards, clinicians not only focus on early diagnosis and treatment of PE but also on long-term prognosis (68). Although the majority of patients with PE resume their daily routines within 6 months to 1 year after discharge, their daily activities remain limited and maintaining adequate physical activity is difficult (54). As a result, new guidelines emphasize the need for rehabilitation during long-term follow-up of patients with PE (3).

As an inexpensive and high-efficiency treatment strategy, pulmonary rehabilitation can significantly improve dyspnea symptoms, overall health and exercise endurance in patients with PE (64). However, due to short application time of pulmonary rehabilitation in patients with $\mathrm{PE}$, no unified rehabilitation model and evaluation criteria have been developed. According to current research results, pulmonary rehabilitation therapy will have no adverse outcomes in patients with PE (62). While the effectiveness is questionable, the majority of research suggests that pulmonary rehabilitation is feasible for patients with PE to improve exercise capacity, relieve dyspnea symptoms and enhance quality of life. Unfortunately, these studies generally suffer from small sample sizes and short follow-up times. In the future, more large-sample, multicenter and rigorous trials are required to investigate more optimized pulmonary rehabilitation programs.

The content of the pulmonary rehabilitation project has garnered particular attention. Exercise training is dominant in pulmonary rehabilitation therapy and works to improve the exercise capabilities of patients to a certain extent (69). There are still some patients who do not improve their lung function with training, and other interventions including health education and psychological intervention, should be implemented to improve pulmonary rehabilitation's effectiveness (37). A previous study demonstrated that $<50 \%$ of patients can maintain pulmonary rehabilitation for $>1$ year (70). For instance, in the implementation plan of pulmonary rehabilitation, continuous exercise training (usually walking and cycling) is important for maintaining benefits and reducing readmission rates (71). It implies that future rehabilitation approaches should prioritize exercise status while also emphasizing health education and psychological counseling for patients with PE. Moreover, previous studies were mainly performed to assess whether the safety and effectiveness of pulmonary rehabilitation program can be adapted to patients with PE or not. Future research should focus on comparing the efficacy and safety of different pulmonary rehabilitation programs head-to-head in patients with $\mathrm{PE}$.

As a serious adverse reaction after a PE, CTEPH can develop into right-sided heart failure, which has a poor prognosis (72). Some researchers have incorporated pulmonary rehabilitation into the treatment plan of patients with CTEPH. A preliminary investigation revealed that home-based, closely supervised pulmonary rehabilitation therapy can safely improve exercise capacity and health-related quality of life in patients with CTEPH (73). In addition, a retrospective analysis demonstrated that a 3-week structured in-patient program (including incremental exercise training, abdominal, upper and lower limb muscle activities, education, nutritional programs and psychosocial counseling) can improve exercise capacity for patients with CTEPH following pulmonary endarterectomy (74). For inoperable CTEPH, 12 weeks of rehabilitation training following balloon pulmonary angioplasty can significantly improve athletic performance and heart failure symptoms with a good safety level (75). The available evidence indicates that patients with acute PE and CTEPH (advanced stage) can benefit from pulmonary rehabilitation.

According to our current knowledge, there are still some unanswered questions: i) Whether the acute period or the stable period is the most beneficial time to allow for pulmonary rehabilitation in patients with PE; ii) whether the intensity of exercise training is comparable to or less than that of daily activities; iii) what duration pulmonary rehabilitation should occur for; and iv) new interventions for patients with PE should be explored in addition to the above six interventions (exercise training, respiratory training, non-invasive ventilation, health education, psychological intervention and nutritional supplementation).

\section{Conclusion}

Pulmonary rehabilitation is an emerging field to be applied in studying patients with PE. Nevertheless, there are presently few studies available on this topic and sufficiently powerful randomized controlled trials are limited. The existing evidence suggests that pulmonary rehabilitation is a potential treatment for alleviating post-PE syndrome, which improves the quality of life and prognosis of patients with PE. More and high-quality prospective studies are required to provide stronger evidence.

\section{Acknowledgements}

Not applicable.

\section{Funding}

The present study was supported by grants from the Medical Health Science and Technology Project of Zhejiang Province (grant nos. 2020KY817 and 2021KY281) and Ningbo Natural Science Foundation Project (grant no. 202003N4274). 


\section{Availability of data and materials}

Not applicable.

\section{Authors' contributions}

AY contributed to conception, design and final approval of the submitted version. WD, WL, JC, WH and AY contributed to completing the table, and writing and revising the paper. All authors have read and approved the final manuscript. Data sharing is not applicable.

\section{Ethics approval and consent to participate}

Not applicable.

\section{Patient consent for publication}

Not applicable.

\section{Competing interests}

The authors declare that they have no competing interests.

\section{References}

1. Zhou H, Tang Y, Wang L, Shi C, Feng Y and Yi Q: Risk factors associated with long-term mortality in patients with pulmonary embolism and the predictive value of Charlson comorbidity index. Zhonghua Yi Xue Za Zhi 96: 273-276, 2016 (In Chinese).

2. Barco S, Mahmoudpour SH, Valerio L, Klok FA, Münzel T, Middeldorp S, Ageno W, Cohen AT, Hunt BJ and Konstantinides SV: Trends in mortality related to pulmonary embolism in the European region, 2000-15: Analysis of vital registration data from the WHO mortality database. Lancet Respir Med 8: 277-287, 2020.

3. Konstantinides SV, Meyer G, Becattini C, Bueno H, Geersing GJ, Harjola VP,Huisman MV,Humbert M, Jennings CS, Jiménez D, et al: 2019 ESC guidelines for the diagnosis and management of acute pulmonary embolism developed in collaboration with the European Respiratory Society (ERS): The task force for the diagnosis and management of acute pulmonary embolism of the European society of cardiology (ESC). Eur Respir J 54: 1901647, 2019.

4. Huisman MV,Barco S, Cannegieter SC,Le Gal G, Konstantinides SV, Reitsma PH, Rodger M, Vonk Noordegraaf A and Klok FA: Pulmonary embolism. Nat Rev Dis Primers 4: 18028, 2018.

5. Ghanima W, Wik HS, Tavoly M,Enden T and Jelsness-Jørgensen LP: Late consequences of venous thromboembolism: Measuring quality of life after deep vein thrombosis and pulmonary embolism. Thromb Res 164: 170-176, 2018.

6. Klok FA, van Kralingen KW, van Dijk AP,Heyning FH, Vliegen HW, Kaptein AA and Huisman MV: Quality of life in long-term survivors of acute pulmonary embolism. Chest 138: 1432-1440, 2010.

7. Konstantinides SV, Torbicki A, Agnelli G, Danchin N, Fitzmaurice D, Galiè N, Gibbs JS, Huisman MV, Humbert M, Kucher N, et al: 2014 ESC guidelines on the diagnosis and management of acute pulmonary embolism. Eur Heart J 35: 3033-3069, 3069a-3069k, 2014.

8. Spruit MA, Singh SJ, Garvey C, ZuWallack R, Nici L, Rochester C, Hill K, Holland AE, Lareau SC, Man WD, et al: An official American thoracic society/European respiratory society statement: Key concepts and advances in pulmonary rehabilitation. Am J Respir Crit Care Med 188: e13-e64, 2013.

9. Güell MR, Cejudo P, Ortega F, Puy MC, Rodríguez-Trigo G, Pijoan JI, Martinez-Indart L, Gorostiza A, Bdeir K, Celli B and Galdiz JB: Benefits of long-term pulmonary rehabilitation maintenance program in patients with severe chronic obstructive pulmonary disease. Three-year follow-up. Am J Respir Crit Care Med 195: 622-629, 2017.

10. Liu X, Wu W, Li N, Li P, Wang Z and Shan C: Effects of water-based Liuzijue exercise on peak exercise capacity, functional exercise capacity, and quality of life in people with COPD. Clin Respir J 15: 956-966, 2021.
11. Zhu Y, Zhu Y, Zhu Y, Ren Q and Zhou T: An analysis of the dynamic changes in the self-efficacy and quality of life of elderly patients with chronic obstructive pulmonary disease following community-based rehabilitation. Am J Transl Res 13: 2745-2751, 2021.

12. Vogelmeier CF, Criner GJ, Martinez FJ, Anzueto A, Barnes PJ, Bourbeau J, Celli BR, Chen R, Decramer M, Fabbri LM, et al: Global strategy for the diagnosis, management, and prevention of chronic obstructive lung disease 2017 report. GOLD executive summary. Am J Respir Crit Care Med 195: 557-582, 2017.

13. Lindenauer PK, Stefan MS, Pekow PS, Mazor KM, Priya A, Spitzer KA, Lagu TC, Pack QR, Pinto-Plata VM and ZuWallack R: Association between initiation of pulmonary rehabilitation after hospitalization for COPD and 1-year survival among medicare beneficiaries. JAMA 323: 1813-1823, 2020.

14. Boon GJAM, Janssen SMJ, Barco S, Bogaard HJ, Ghanima W, Kroft LJM, Meijboom LJ, Ninaber MK, Nossent EJ, Spruit MA, et al: Efficacy and safety of a 12-week outpatient pulmonary rehabilitation program in Post-PE syndrome. Thromb Res 206: 66-75, 2021.

15. Nolan CM, Polgar O, Schofield SJ, Patel S, Barker RE, Walsh JA, Ingram KA, George PM, Molyneaux PL, Maher TM and Man WD: Pulmonary rehabilitation in idiopathic pulmonary fibrosis and COPD: A propensity matched real-world study. Chest, Oct 23, 2021 (Epub ahead of print).

16. Nilsson LT, Andersson T, Larsen F, Lang IM, Liv P and Söderberg S: Dyspnea after pulmonary embolism: A nation-wide population-based case-control study. Pulm Circ 11: $20458940211046831,2021$.

17. Wang Z, Sun Y and An Y: Reduced exercise training on the rehabilitation status of patients with acute pulmonary embolism. Sci Technol Eng 17: 154-159, 2017 (In Chinese).

18. Lakoski SG, Savage PD, Berkman AM, Penalosa L, Crocker A, Ades PA, Kahn SR and Cushman M: The safety and efficacy of early-initiation exercise training after acute venous thromboembolism: A randomized clinical trial. J Thromb Haemost 13: 1238-1244, 2015.

19. Nopp S, Klok FA, Moik F, Petrovic M, Derka I, Ay C and Zwick RH: Outpatient pulmonary rehabilitation in patients with persisting symptoms after pulmonary embolism. J Clin Med 9: 1811, 2020.

20. Lin HY, Lin CY and Shen MC: Review article inferior vena cava thrombosis: A case series of patients observed in Taiwan and literature review. Thromb J 19: 43, 2021.

21. Panahi L, Udeani G, Horseman M, Weston J, Samuel N, Joseph M, Mora A and Bazan D: Review of medical therapies for the management of pulmonary embolism. Medicina (Kaunas) 57: 110,2021

22. Depietri L, Marietta M, Scarlini S, Marcacci M, Corradini E, Pietrangelo A and Ventura P: Clinical impact of application of risk assessment models (Padua prediction score and improve bleeding score) on venous thromboembolism, major hemorrhage and health expenditure associated with pharmacologic VTE prophylaxis: A 'real life' prospective and retrospective observational study on patients hospitalized in a single internal medicine unit (the STIME study). Intern Emerg Med 13: 527-534, 2018.

23. From the American Association of Neurological Surgeons (AANS), American Society of Neuroradiology (ASNR), Cardiovascular and Interventional Radiology Society of Europe (CIRSE), Canadian Interventional Radiology Association (CIRA), Congress of Neurological Surgeons (CNS), European Society of Minimally Invasive Neurological Therapy (ESMINT), European Society of Neuroradiology (ESNR), European Stroke Organization (ESO), Society for Cardiovascular Angiography and Interventions (SCAI), Society of Interventional Radiology (SIR), et al: Multisociety consensus quality improvement revised consensus statement for endovascular therapy of acute ischemic stroke. Int J Stroke 13: 612-632, 2018.

24. Goldhaber SZ: Risk factors for venous thromboembolism. J Am Coll Cardiol 56: 1-7, 2010.

25. Klok FA, Tijmensen JE, Haeck ML, van Kralingen KW and Huisman MV: Persistent dyspnea complaints at long-term follow-up after an episode of acute pulmonary embolism: Results of a questionnaire. Eur J Intern Med 19: 625-629, 2008.

26. Tavoly M, Utne KK, Jelsness-Jørgensen LP, Wik HS, Klok FA, Sandset PM and Ghanima W: Health-related quality of life after pulmonary embolism: A cross-sectional study. BMJ Open 6: e013086, 2016. 
27. Yang S, Yang Y, Zhai Z, Kuang T, Gong J, Zhang S, Zhu J, Liang L, Shen YH and Wang C: Incidence and risk factors of chronic thromboembolic pulmonary hypertension in patients after acute pulmonary embolism. J Thorac Dis 7: 1927-1938, 2015.

28. Ende-Verhaar YM, Cannegieter SC, Vonk Noordegraaf A, Delcroix M, Pruszczyk P, Mairuhu AT, Huisman MV and Klok FA: Incidence of chronic thromboembolic pulmonary hypertension after acute pulmonary embolism: A contemporary view of the published literature. Eur Respir J 49: 1601792, 2017.

29. Klok FA, van der Hulle T, den Exter PL, Lankeit M, Huisman MV and Konstantinides S: The post-PE syndrome: A new concept for chronic complications of pulmonary embolism. Blood Rev 28 221-226, 2014

30. Hunter R, Lewis S, Noble S, Rance J and Bennett PD: 'Post-thrombotic panic syndrome': A thematic analysis of the experience of venous thromboembolism. Br J Health Psychol 22: $8-25,2017$

31. Fabyan KD and Holley AB: Postpulmonary embolism syndrome. Curr Opin Pulm Med 27: 335-341, 2021.

32. Boon GJAM, Huisman MV and Klok FA: Determinants and management of the post-pulmonary embolism syndrome. Semin Respir Crit Care Med 42: 299-307, 2021.

33. Alonso-Martínez JL, Anniccherico-Sánchez FJ and Urbieta-Echezarreta MA: The post-pulmonary embolism (post-PE syndrome). Eur J Intern Med 76: 127-129, 2020.

34. Kahn SR, Hirsch AM, Akaberi A, Hernandez P, Anderson DR Wells PS, Rodger MA, Solymoss S, Kovacs MJ, Rudski L, et al: Functional and exercise limitations after a first episode of pulmonary embolism: Results of the ELOPE prospective cohort study. Chest 151: 1058-1068, 2017.

35. Kahn SR, Akaberi A, Granton JT, Anderson DR, Wells PS, Rodger MA, Solymoss S, Kovacs MJ, Rudski L, Shimony A, et al: Quality of life, dyspnea, and functional exercise capacity following a first episode of pulmonary embolism: Results of the ELOPE cohort study. Am J Med 130: 990.e9-990.e21, 2017.

36. Valerio L, Barco S, Jankowski M, Rosenkranz S, Lankeit M, Held M, Gerhardt F, Bruch L, Ewert R, Faehling M, et al: Quality of life 3 and 12 months following acute pulmonary embolism: Analysis from a prospective multicenter cohort study. Chest 159: 2428-2438, 2021

37. Shenoy MA and Paul V: Pulmonary rehabilitation. In: StatPearls, Treasure Island (FL), StatPearls Publishing, 2021.

38. Jiang Y, Guo J, Sun P, Chen Z, Liu F, Wang S and Ding Z: Perceptions and experiences of older patients and healthcare professionals regarding shared decision-making in pulmonary rehabilitation: A qualitative study. Clin Rehabil 35: 1627-1639, 2021.

39. Silva IS, Fregonezi GA, Dias FA, Ribeiro CT, Guerra RO and Ferreira GM: Inspiratory muscle training for asthma. Cochrane Database Syst Rev 2013: CD003792, 2013.

40. Arnedillo A, Gonzalez-Montesinos JL, Fernandez-Santos JR Vaz-Pardal C, España-Domínguez C, Ponce-González JG and Cuenca-García M: Effects of a rehabilitation programme with a nasal inspiratory restriction device on exercise capacity and quality of life in COPD. Int J Environ Res Public Health 17: 3669 , 2020.

41. McCreery JL, Mackintosh KA, Mills-Bennett R and McNarry MA: The effect of a high-intensity PrO2Fit inspiratory muscle training intervention on physiological and psychological health in adults with bronchiectasis: A mixed-methods study. Int J Environ Res Public Health 18: 3051, 2021.

42. Zampogna E, Zappa M, Spanevello A and Visca D: Pulmonary rehabilitation and asthma. Front Pharmacol 11: 542, 2020.

43. Bernardi E, Pomidori L, Bassal F, Contoli M and Cogo A: Respiratory muscle training with normocapnic hyperpnea improves ventilatory pattern and thoracoabdominal coordination, and reduces oxygen desaturation during endurance exercise testing in COPD patients. Int J Chron Obstruct Pulmon Dis 10 1899-1906, 2015

44. Fekete M, Kerti M, Fazekas-Pongor V, Balazs P, Csizmadia Z, Nemeth AN, Tarantini S and Varga JT: Effect of interval training with non-invasive ventilation in severe chronic obstructive pulmonary disease-a prospective cohort study with matched control group. Ann Palliat Med 10: 5289-5298, 2021.

45. Cortegiani A, Longhini F, Madotto F, Groff P, Scala R, Crimi C, Carlucci A, Bruni A, Garofalo E, Raineri SM, et al: High flow nasal therapy versus noninvasive ventilation as initial ventilatory strategy in COPD exacerbation: A multicenter non-inferiority randomized trial. Crit Care 24: 692, 2020.
46. Ergan B, Oczkowski S, Rochwerg B, Carlucci A, Chatwin M, Clini E, Elliott M, Gonzalez-Bermejo J, Hart N, Lujan M, et al: European respiratory society guidelines on long-term home non-invasive ventilation for management of COPD. Eur Respir J 54: 1901003, 2019

47. Padilha GA, Horta LF, Moraes L, Braga CL, Oliveira MV, Santos CL, Ramos IP, Morales MM, Capelozzi VL, Goldenberg RC, et al: Comparison between effects of pressure support and pressure-controlled ventilation on lung and diaphragmatic damage in experimental emphysema. Intensive Care Med Exp 4: 35, 2016.

48. Roberts NJ, Kidd L, Kirkwood K, Cross J and Partridge MR: How is the education component of pulmonary rehabilitation delivered in practice-is it patient-centred? Clin Respir J 15: 835-842, 2021

49. Janssen SM, Vliet Vlieland TP, Volker G, Spruit MA and Abbink JJ: Pulmonary rehabilitation improves self-management ability in subjects with obstructive lung disease. Respir Care 66: 1271-1281, 2021.

50. Popa-Velea O and Purcarea VL: Psychological intervention-a critical element of rehabilitation in chronic pulmonary diseases. J Med Life 7: 274-281, 2014.

51. Habib GMM, Rabinovich R, Divgi K, Ahmed S, Saha SK, Singh S, Uddin A, Uzzaman MN and Pinnock H: Systematic review of clinical effectiveness, components, and delivery of pulmonary rehabilitation in low-resource settings. NPJ Prim Care Respir Med 30: 52, 2020.

52. Højen AA, Dreyer PS, Lane DA, Larsen TB and Sørensen EE: Adolescents' and young adults' lived experiences following venous thromboembolism: 'It will always lie in wait'. Nurs Res 65: 455-464, 2016.

53. Noble $\mathrm{S}$, Lewis R, Whithers J, Lewis $\mathrm{S}$ and Bennett P: Long-term psychological consequences of symptomatic pulmonary embolism: A qualitative study. BMJ Open 4: e004561, 2014.

54. Rolving N, Brocki BC and Andreasen J: Coping with everyday life and physical activity in the aftermath of an acute pulmonary embolism: A qualitative study exploring patients' perceptions and coping strategies. Thromb Res 182: 185-191, 2019.

55. Kowal C, Peyre H, Amad A, Pelissolo A, Leboyer M, Schürhoff F and Pignon B: Psychotic, mood, and anxiety disorders and venous thromboembolism: A systematic review and meta-analysis. Psychosom Med 82: 838-849, 2020.

56. Wierenga KL, Fresco DM, Alder M, Sattar A and Moore SM: Preliminary efficacy of an emotion regulation intervention on physical activity and depressive and anxious symptoms in individuals in cardiac rehabilitation. J Cardiovasc Nurs, Jul 23, 2021 (Online ahead of print).

57. Mete B, Pehlivan E, Gülbaş G and Günen H: Prevalence of malnutrition in COPD and its relationship with the parameters related to disease severity. Int J Chron Obstruct Pulmon Dis 13: 3307-3312, 2018

58. Miki K and Maekura R: Nutrition management for COPD. Nihon Rinsho 74: 801-806, 2016 (In Japanese).

59. Hsieh MJ, Yang TM and Tsai YH: Nutritional supplementation in patients with chronic obstructive pulmonary disease. J Formos Med Assoc 115: 595-601, 2016.

60. Ries AL, Bauldoff GS, Carlin BW, Casaburi R, Emery CF, Mahler DA, Make B, Rochester CL, Zuwallack R and Herrerias C: Pulmonary rehabilitation: Joint ACCP/AACVPR evidence-based clinical practice guidelines. Chest 131 (5 Suppl): 4S-42S, 2007.

61. Noack F, Schmidt B, Amoury M, Stoevesandt D, Gielen S, Pflaumbaum B, Girschick C, Völler H and Schlitt A: Feasibility and safety of rehabilitation after venous thromboembolism. Vasc Health Risk Manag 11: 397-401, 2015.

62. Cires-Drouet RS, Mayorga-Carlin M, Toursavadkohi S, White R Redding E, Durham F, Dondero K, Prior SJ, Sorkin JD and Lal BK: Safety of exercise therapy after acute pulmonary embolism. Phlebology 35: 824-832, 2020 .

63. Amoury M, Noack F, Kleeberg K, Stoevesandt D, Lehnigk B, Bethge S, Heinze V and Schlitt A: Prognosis of patients with pulmonary embolism after rehabilitation. Vasc Health Risk Manag 14: 183-187, 2018.

64. Rolving N, Brocki BC, Bloch-Nielsen JR, Larsen TB, Jensen FL, Mikkelsen HR, Ravn P and Frost L: Effect of a physiotherapist-guided home-based exercise intervention on physical capacity and patient-reported outcomes among patients with acute pulmonary embolism: A randomized clinical trial. JAMA Netw Open 3: e200064, 2020. 
65. Haukeland-Parker S, Jervan Ø, Johannessen HH, Gleditsch J, Stavem K, Steine K, Spruit MA, Holst R, Tavoly M, Klok FA and Ghanima W: Pulmonary rehabilitation to improve physical capacity, dyspnea, and quality of life following pulmonary embolism (the PeRehab study): Study protocol for a two-center randomized controlled trial. Trials 22: 22, 2021.

66. Yang Y, Liang L, Zhai Z, He H, Xie W, Peng X and Wang C; Investigators for National Cooperative Project for Prevention and Treatment of PTE-DVT: Pulmonary embolism incidence and fatality trends in chinese hospitals from 1997 to 2008: A multicenter registration study. PLoS One 6: e26861, 2011.

67. Becattini C, Agnelli G, Lankeit M, Masotti L, Pruszczyk P, Casazza F, Vanni S, Nitti C, Kamphuisen P, Vedovati MC, et al: Acute pulmonary embolism: Mortality prediction by the 2014 European society of cardiology risk stratification model. Eur Respir J 48: 780-786, 2016.

68. Sandal A, Korkmaz ET, Aksu F, Köksal D, Toros Selçuk Z, Demir AU, Emri S and Cöplü L: Performance of pulmonary embolism severity index in predicting long-term mortality after acute pulmonary embolism. Anatol J Cardiol 25: 544-554, 2021.

69. Xu L, Fu C, Zhang Q, He C and Wei Q: The effectiveness of exercise training in treating venous thromboembolism: A systematic review. Phys Sportsmed 49: 1-11, 2021.

70. Spencer LM and McKeough ZJ: Maintaining the benefits following pulmonary rehabilitation: Achievable or not? Respirology 24: 909-915, 2019.
71. Alison JA, McKeough ZJ, Johnston K, McNamara RJ Spencer LM, Jenkins SC, Hill CJ, McDonald VM, Frith P, Cafarella P, et al: Australian and New Zealand pulmonary rehabilitation guidelines. Respirology 22: 800-819, 2017.

72. Catella-Chatron J, Merah A, De Magalhaes E, Moulin N, Accassat S, Duvillard C, Mismetti P and Bertoletti L: Chronic thromboembolic pulmonary hypertension suspicion after pulmonary embolism in cancer patients. Respir Med Res 76: 34-37, 2019.

73. Inagaki T, Terada J, Tanabe N, Kawata N, Kasai H, Sugiura T, Shigeta A, Asano Y, Murata A, Tsushima K, et al: Home-based pulmonary rehabilitation in patients with inoperable or residual chronic thromboembolic pulmonary hypertension: A preliminary study. Respir Investig 52: 357-364, 2014.

74. La Rovere MT, Pinna GD, Pin M, Bruschi C, Callegari G, Zanotti E, D'Armini A and Ambrosino N: Exercise training after pulmonary endarterectomy for patients with chronic thromboembolic pulmonary hypertension. Respiration 97: 234-241, 2019.

75. Fukui S, Ogo T, Takaki H, Ueda J, Tsuji A, Morita Y, Kumasaka R, Arakawa T, Nakanishi M, Fukuda T, et al: Efficacy of cardiac rehabilitation after balloon pulmonary angioplasty for chronic thromboembolic pulmonary hypertension. Heart 102: 1403-1409, 2016. 